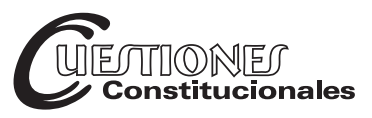

Revista Mexicana de Derecho Constitucional

Núm. 41, julio-diciembre 2019

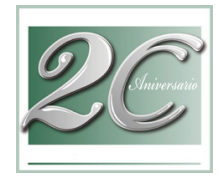

Los derechos y garantías de fuente local en la doctrina de la Suprema

Corte de Justicia de la Nación. Particular referencia a la carta de derechos de la Ciudad de México

César Astudillo*

SUMARIO: I. Preliminar. II. La posición de la SCJN ante los derechos humanos de fuente estatal. III. La doctrina jurisprudencial en torno a las garantías de los derechos humanos de fuente estatal.

\title{
I. PRELIMINAR
}

La Constitución de la Ciudad de México —en adelante Constitución de la $\mathrm{CdMx}$ - representa uno de los acontecimientos jurídicos más trascendentes de este siglo, cuya promulgación, contemporáneamente a la conmemoración del centenario de la Constitución general de la República, ha desencadenado una nueva deliberación académica que todavía aguarda un análisis detenido y puntual en torno a la relación entre el orden constitucional nacional y los órdenes locales.

El nacimiento de una nueva entidad integrante de la Federación mexicana, caracterizada por ser al mismo tiempo una especie de ciudad-Estado, capital del país, asiento de los poderes federales y sede de la zona metropolitana más extensa de la República, ha abierto distintas líneas de investigación

\footnotetext{
* Investigador titular en el Instituto de Investigaciones Jurídicas de la UNAM. Agradezco a la maestra Caridad Hernández Zenteno el apoyo brindado en la búsqueda y clasificación de la información que utilicé en la presente contribución. Asimismo, a la licenciada María Elena Antuna González, a quien se debe el diligente cuidado en la revisión formal del texto.
} 
que han salido a la luz luego del intenso proceso constituyente de la Ciudad de México - $\mathrm{CdMx}$ - , con motivo del peculiar régimen jurídico con el que se ha reivindicado la especial naturaleza de la capital de la República.

Una de las problemáticas más significativas a este respecto tiene que ver con una interrogante clave que ha adquirido particular relevancia en un momento histórico como en el que nos encontramos, y dentro de un contexto institucional como el que vivimos actualmente, y que se cuestiona, ¿cuál es la función de las entidades federativas en el reconocimiento de derechos y libertades?

No hay duda que las Constituciones tienen en los derechos a uno de los componentes genéticos que las caracterizan, en tanto expresión de una competencia estatal dentro de un modelo federal. Sin embargo, el robusto catálogo de derechos incorporado a la Constitución de la $\mathrm{CdMx}$ ha vuelto a abrir un capítulo problemático que ya no tiene que ver con la relación entre la dualidad de órdenes constitucionales, sino más específicamente con la forma en la que se integran e interactúan los catálogos de derechos contenidos en ellos.

Esta definición cobra notoriedad porque se presenta al interior de una tendencia que desde 2011 se ha orientado a descomprimir las fuentes de los derechos humanos en el ordenamiento jurídico mexicano, y dentro de un ámbito temporal en el que la doctrina jurisprudencial de la Suprema Corte de Justicia de la Nación (SCJN) sigue dando pasos para institucionalizar la relación entre las declaraciones de derechos que descienden de la Constitución Política de los Estados Unidos Mexicanos (en adelante CPEUM) y los tratados y convenciones internacionales, y a la que buscan sumarse las cartas de derechos estatales, en su afán por alcanzar el reconocimiento como fuentes primigenias de derechos y libertades.

La presente contribución busca analizar de qué manera nuestro máximo tribunal se ha ido aproximando al reconocimiento, la naturaleza, función e integración de los derechos reconocidos en las Constituciones estatales de nuestro país, así como a las garantías procesales dispuestas para su efectiva protección judicial.

Lo anterior sin dejar de destacar que carecemos aún de aproximaciones jurisprudenciales incluso en torno al significado y la posición jurídica de las Constituciones estatales dentro del ordenamiento nacional. No olvidemos que, sobre su posición en el sistema de fuentes del ordenamiento mexicano, la SCJN destacó inicialmente que las mismas conforman "normas generales subordinadas al Pacto Federal" y, por ende, a la ley fundamental, y que 
más tarde señalaría que en lo que toca a sus regímenes internos, "es dable considerar sus preceptos como normas autónomas respecto de la CPEUM, en términos materiales y formales". ${ }^{1}$

Ocupa una atención especial lo que la SCJN expresó con motivo de la Acción de Inconstitucionalidad 15/2017 y acumuladas 16, 18 y 19/2017, en la que se impugnaron distintos contenidos de la Constitución de la CdMx, no sólo porque es la más reciente aproximación a los derechos de fuente estatal por parte de nuestro máximo tribunal, sino porque la resolución representa el estudio más profundo que hasta ahora ha llevado a cabo sobre el significado de los catálogos de derechos humanos de las Constituciones estatales, su ámbito competencial, alcance e interpretación, y en torno a los instrumentos procesales de tutela jurisdiccional de dicha carta.

\section{LA POSICIÓN DE LA SCJN ANTE LOS DERECHOS HUMANOS} DE FUENTE ESTATAL

\section{Aproximación federalista a los derechos}

El análisis y las definiciones jurisprudenciales en torno a los derechos humanos, su reconocimiento y protección en el contexto de nuestro modelo federal de Estado son relativamente recientes. De hecho, no van más allá de los comienzos del nuevo siglo, luego de que la reforma integral de la Constitución del Estado de Veracruz fuera cuestionada ante la SCJN. ${ }^{2}$

1 Es necesario destacar que carecemos aún de aproximaciones jurisprudenciales en torno a la naturaleza, el significado, la función y la posición jurídica de las Constituciones estatales dentro del ordenamiento nacional. Sobre su posición en el sistema de fuentes del ordenamiento mexicano, la Corte destacó inicialmente que las mismas son "normas generales subordinadas al Pacto Federal" y, por ende, a la ley fundamental; más tarde señaló que en lo que toca a sus regímenes internos, "es dable considerar sus preceptos como normas autónomas respecto de la CPEUM, en términos materiales y formales". Aun así, hasta ahora no ha determinado la concreta posición que guardan en relación con la Constitución mexicana, ni en relación con las leyes generales. Véase la Tesis P./J. 16/2001, de rubro: “ACCIÓN DE INCONSTITUCIONALIDAD. ES PROCEDENTE PARA IMPUGNAR CONSTITUCIONES LOCALES, AL SER ÉSTAS, NORMAS DE CARÁCTER GENERAL Y ESTAR SUBORDINADAS A LA CONSTITUCIÓN FEDERAL", publicada en el Semanario Judicial de la Federación y su Gaceta, Novena Época, t. XIII, marzo de 2001, p. 447, registro digital: 190236. Tesis 2a. CXXVII/2010, p. 1471.

2 Sobre el particular, acúdase a Astudillo, César, Derecho procesal constitucional local, México, Porrúa-Instituto Mexicano de Derecho Procesal Constitucional, 2017, pp. 5 y ss. 
En una primera etapa, que podemos denominar de federalismo de los derechos, nuestro máximo tribunal, sin entrar a explicitar su fundamento, validó que una Constitución estatal pudiera contener un catálogo de derechos humanos, concebidos como aquellos que "expresamente se reserva el pueblo" de dicha entidad. ${ }^{3}$ Ese primer acercamiento condujo también a la inicial afirmación de que las entidades federativas pueden establecer mecanismos de control constitucional a nivel local para la tutela de los derechos locales y del entero ordenamiento constitucional, como veremos más adelante. ${ }^{4}$

Los derechos y sus garantías al interior de las entidades federativas han evolucionado desde entonces, dando oportunidad a que paulatinamente se vayan definiendo sus contornos.

Con motivo de la reforma constitucional sobre derechos de las personas indígenas de agosto de 2001, la SCJN tuvo una aproximación inicial al significado del doble reconocimiento de los mismos derechos por parte de la CPEUM y de las Constituciones estatales, y al papel que estas últimas cumplen en ese proceso. Subrayó que los derechos reconocidos por la CPEUM no pueden restringirse ni suspenderse, "sin embargo, sí son susceptibles de ser ampliados" a nivel local, con el propósito de pormenorizarlos y procurar "su mejor aplicación y observancia". Asimismo, sostuvo que dichos derechos deben ser considerados como "derechos mínimos que deben ser respetados para garantizar su efectividad, pero que pueden ser ampliados para imprimir las características propias que mejor expresen las situaciones y aspiraciones de sus pueblos indígenas, siempre que tal ampliación se realice sin vulnerar el marco constitucional al que dichos derechos se encuentran sujetos" (énfasis añadido). Sostuvo, en este sentido, que la regulación de

\footnotetext{
3 Controversia Constitucional 16/2000, del 09 de mayo de 2002, pp. 174-176.

4 Idem. De dicha controversia emanó la Tesis: P. XXXIII/2002, de rubro: "CONTROVERSIA CONSTITUCIONAL. LA FACULTAD OTORGADA A LA SALA CONSTITUCIONAL DEL TRIBUNAL SUPERIOR DE JUSTICIA DEL ESTADO DE VERACRUZ-LLAVE PARA CONOCER Y RESOLVER EL JUICIO DE PROTECCIÓN DE DERECHOS HUMANOS, PREVISTO EN LA CONSTITUCIÓN POLÍTICA DE ESA ENTIDAD FEDERATIVA, NO INVADE LA ESFERA DE ATRIBUCIONES DE LOS TRIBUNALES DE LA FEDERACIÓN, PUES AQUÉL SE LIMITA A SALVAGUARDAR, EXCLUSIVAMENTE, LOS DERECHOS HUMANOS QUE ESTABLECE EL PROPIO ORDENAMIENTO LOCAL", publicada en el Semanario Judicial..., cit., Novena Época, t. XVI, agosto de 2002, p. 903.

5 Tesis 2a. CXXXIX/2002, de rubro: "DERECHOS DE LOS INDíGENAS. LOS ESTABLECIDOS EN LA CONSTITUCIÓN POLÍTICA DE LOS ESTAdOS UNIDOS MEXICANOS PUEDEN SER AMPLIADOS POR LAS LEGISLATURAS LOCALES DENTRO DEL MARCO DE AQUÉLLA", publicada en el Semanario Judicial..., cit., Novena Época, t. XVI, noviembre de 2002, p. 446.
} 
los derechos en la CPEUM deja un importante espacio de libertad configurativa en favor de las entidades federativas, para que puedan perfilarlos con base en su propio contexto, sus fines particulares, y los requerimientos de su realidad social; de ahí que si con anterioridad se encontraban consagrados derechos en beneficio de los indígenas, debían considerarse como suplementarios a los derechos mínimos a satisfacer, que para este efecto se erigían como "postulados básicos de unidad e indivisibilidad nacional". 6

En la Contradicción de Tesis 350/2009 mantuvo su criterio al destacar que el "federalismo constitucional autoriza que las constituciones locales amplíen el nivel de protección de los derechos humanos, lo cual implica la posibilidad de que no exista coincidencia entre lo previsto en la Constitución General y las constituciones locales". Evidentemente, el elevar los niveles de protección de los derechos se concebía como la consecuencia necesaria de avalar que en esta materia "las entidades federativas gozan de un cierto margen decisorio". 7

Nuestro máximo tribunal acotó, no obstante, que dentro de ese margen de libertad, lo que no podían hacer los órdenes jurídicos locales era "afectar el contenido esencial de las garantías individuales reconocidas en la norma suprema", ${ }^{8}$ ni introducir "restricciones indebidas" que atentasen contra derechos reconocidos dentro del orden constitucional y convencional, pues su reconocimiento y amplitud "solamente podría estar establecido en la Constitución Política de los Estados Unidos Mexicanos y no individual o aisladamente en las Constituciones de los Estados". ${ }^{9}$ Con estos pronunciamientos comenzó a pergeñarse la embrionaria existencia de un estándar de protección mínimo a garantizar por los jueces de los derechos humanos, así como la determinación de prohibiciones normativas específicas.

6 Tesis 2a. CXL/2002, de rubro: "DERECHOS DE LOS INDÍGENAS. LOS ESTABLECIDOS EN LAS LEGISLACIONES LOCALES EN FAVOR DE ELLOS NO FUERON LIMITADOS POR LAS REFORMAS A LA CONSTITUCIÓN FEDERAL EN LA MATERIA, VIGENTES A PARTIR DEL QUINCE DE AGOSTO DE DOS MIL UNO", publicada en el Semanario Judicial..., cit., Novena Época, t. XVI, noviembre de 2002, p. 446.

7 Contradicción de Tesis 350/2009, del 6 de mayo de 2010, foja 37. De ella derivó el criterio: Tesis P/J 68/2010, de rubro: “AMPARO DIRECTO. PROCEDE CONTRA LAS SENTEN-

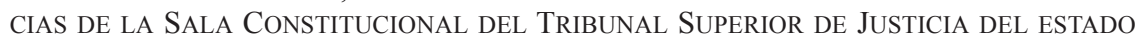
DE VERACRUZ, EN MATERIA DE DERECHOS HUMANOS, SALVO TRATÁNDOSE DE CUESTIONES ELECTORALES", publicada en el Semanario Judicial..., cit., Novena Época, t. XXXII, agosto de 2010, p. 5.

8 Contradicción de Tesis 350/2009, del 6 de mayo de 2010, foja 38.

9 Acción de Inconstitucionalidad 11/2009, del 28 de septiembre 2011, p. 86. 
El juicio de amparo sirvió igualmente para que la SCJN pudiera aproximarse al tema en análisis, asintiendo que "efectivamente las entidades federativas están facultades para gobernarse de acuerdo con su propia Constitución donde válidamente pueden establecer derechos fundamentales y un juicio local para su protección, dentro de los propios límites que establezca la Constitución Federal, lo cual implica no invadir la competencia del Poder Judicial de la Federación". ${ }^{10}$

\section{Concepción centralista de los derechos}

Más próximos en el tiempo, en un inesperado giro interpretativo, la SCJN incursionó en una nueva etapa, que podríamos denominar de centralismo de los derechos, caracterizada por su pretensión de incidir en la manera en que los órganos jurisdiccionales estatales debían concebir y aplicar el parámetro de regularidad constitucional.

Al resolver la Acción de Inconstitucionalidad 75/2015, nuestro tribunal constitucional determinó que el parámetro de regularidad constitucional integrado por los derechos de fuente constitucional, convencional, y por la jurisprudencia nacional e interamericana, se encuentra previsto y definido por la CPEUM y, en esa medida, "no hay materia para la competencia de los Estados sobre este punto, al ser un tema inherente al orden jurídico constitucional". ${ }^{11}$ Buscó subrayar con ello que la competencia legislativa estatal no estaba habilitada para desconocer dichos derechos, ni el alcance interpretativo que les ha sido asignado por sus intérpretes privilegiados.

Imbuida en esta ruta hermenéutica, la SCJN sostuvo "que la Constitución Federal consagró de manera implícita la facultad a favor del Congreso de la Unión de expedir las leyes reglamentarias de los derechos humanos contenidos en la Constitución, a fin de establecer sus alcances" (énfasis añadido). ${ }^{12}$ De este modo, y por paradójico que parezca, en aras de justificar

\footnotetext{
10 Amparo Directo en Revisión 3057/2014, del 4 de febrero de 2015, p. 22. El criterio quedó asentado en la Tesis XXXVIII/2016 (10a.), de rubro: "TRIBUNALES CONSTITUCIONALES LOCALES. CARECEN DE COMPETENCIA PARA CONOCER DE ASUNTOS RELACIONADOS CON VIOLACIONES A LA CONSTITUCIÓN PolítiCA DE LOS ESTAdOS UNIDOS MEXICANOS", publicada en la Gaceta del Semanario Judicial..., cit., Décima Época, libro 27, febrero de 2016, p. 686, registro digital: 2010978.

11 Acción de Inconstitucionalidad 75/2015, del 14 de junio de 2016, pp. 61 y ss.

12 Idem.
} 
una inhabilitación negativa, la Corte terminó por centralizar en la Federación la regulación de los derechos humanos, excluyendo definitivamente a las entidades federativas de una libertad configurativa que no de ahora, sino históricamente, ha servido para ir reconociendo derechos adicionales o redimensionando los que le son obligatorios.

Sobre el parámetro, fue enfática al subrayar que

...no corresponde a Legislaturas de los Estados reglamentarlo, matizarlo o de cualquier forma referirse a él, no solamente porque carecen de competencia para ello, sino porque, de permitirse esa regulación podría generar un esquema diferenciado y múltiple en cada una de las entidades federativas, lo que lejos de coadyuvar a la generación de criterios uniformes y homogéneos en materia de la protección de derechos humanos en el Estado mexicano, se traduciría en el detrimento de tales derechos en perjuicio de las personas [énfasis añadido]..$^{13}$

Con esta afirmación terminó de desmoronarse la diferenciación estatal basada en las especificidades históricas, geográficas o culturales, en nombre de una pretendida homologación en beneficio de las personas.

Este cambio de ciento ochenta grados, basado fundamentalmente en la confusión conceptual entre la vocación sustancial del bloque y procesal del parámetro de constitucionalidad, condujo a la afirmación de que las entidades federativas carecen de competencia para hacer suyos determinados contenidos constitucionales, darles una especificidad estatal, prever desarrollos institucionales que les confieran una mayor eficacia y estipular otras modalidades de protección para asegurar su cumplimiento. ${ }^{14}$ Las contradicciones en que incurrió el criterio asumido quedaron de manifiesto en el voto concurrente del ministro Zaldívar, y particular del ministro Ortiz Mena. ${ }^{15}$

\footnotetext{
13 Ibidem, p. 63.

14 El voto concurrente del ministro Zaldívar patentiza esta "confusión" entre una cuestión sustantiva y una cuestión adjetiva. En su opinión, "el principal problema con la argumentación de la sentencia consiste en que confunde la falta de competencia para incidir en la configuración del parámetro de regularidad constitucional, con la falta de competencia para regular el control difuso de constitucionalidad o convencionalidad"; ibidem, p. 65. En torno a la distinción entre el bloque y el parámetro, remitimos a lo expuesto en Astudillo, César, El bloque y el parámetro de constitucionalidad en México, México, UNAM-Tirant Lo Blanch, 2014, pp. 35-37.
}

15 Acción de Inconstitucionalidad 75/2015, cit., pp. 65 y 67, respectivamente. 
Un par de semanas después, al resolver la Acción de Inconstitucionalidad $87 / 2015$, la SCJN volvió a reconocer que el legislador estatal, de conformidad con sus competencias, está habilitado para "desarrollar o incluso ampliar" el contenido de un derecho humano previsto en la CPEUM o en los tratados internacionales, pero acotó, de inmediato, que

...esta facultad no implica que las legislaturas estatales puedan introducir en sus respectivas leyes, definiciones especificas respecto a un derecho humano reconocido en algún ordenamiento de fuente constitucional, pues con ello se pretende contextualizar la naturaleza de este mismo, no obstante que el contenido y alcance del derecho ya se encuentra tutelado y delimitado por la propia norma suprema de la cual dimana [énfasis añadido].

\section{Lo anterior llevó a la SCJN a considerar que}

...el legislador estatal carece de competencia para establecer definiciones de derechos humanos que son reconocidos por la norma suprema, ya que al derivar del orden constitucional, su contenido y alcance no resulta disponible para las entidades federativas, pues de lo contrario se desnaturalizaría su función normativa, jerárquica, universal y de contenido superior respecto al resto de las normas del orden jurídico [énfasis añadido]. ${ }^{16}$

La argumentación, abiertamente contradictoria, sostiene que el legislador puede ampliar el contenido de los derechos en la legislación estatal, pero sin establecer definiciones específicas; que tiene facultades para desarrollarlos, pero sin contextualizarlos, porque al hacerlo se extralimita en sus atribuciones, en virtud de que su alcance se encuentra establecido en las fuentes primigenias de las que emanan. ${ }^{17}$ Esta aproximación no parece haber otorgado el reconocimiento de derechos humanos a los derivados de una fuente estatal, pues volvió a introducir el principio jerárquico y el contenido superior de los estatuidos en las fuentes primigenias, impidiendo que las relaciones entre ellos se rijan bajo los principios pro persona y de interpretación conforme.

En este sentido, coincidimos con la opinión expresada por el ministro Ortiz Mena cuando refiere que

\footnotetext{
16 Acción de Inconstitucionalidad 87/2015, del 30 de junio de 2016, pp. 64 y 65.

17 Por ello, en su voto concurrente, el ministro Ortiz Mena sostuvo que la afirmación de la mayoría de ministros "no soporta un simple análisis lógico". Idem.
} 
...esa argumentación resulta contraria a la forma en que nuestro modelo constitucional, por una parte, consagra al federalismo, y, por la otra, porque se distorsiona la forma apropiada de entender a los derechos humanos como principios irradiadores a todo el sistema controlables desde el valor de la coherencia normativa.

Dicha decisión abona a la limitación, cada vez mayor, de la posibilidad de un constitucionalismo multi-nivel de protección de los derechos humanos, sensible a las preferencias mayoritarias en cada estado. Con este criterio, se limita a los estados oponerse a los derechos humanos y explorar nuevas formas de protección desde la creatividad de los procesos democráticos regionales. En otras palabras, se limita la posibilidad de encontrar en los estados laboratorios democráticos de experimentación, como se ha reconocido en la jurisprudencia americana, que produzcan experiencias de la mejor manera de proteger principios constitucionales, lo que paradójicamente se ha hecho en nombre del federalismo para garantizar una visión centralista cuyo único valor sea la certeza y uniformidad. ${ }^{18}$

La concepción, hasta entonces asumida sobre los derechos, resultó altamente contradictoria porque se produjo en un momento en que la SCJN buscaba afianzar su identidad como tribunal constitucional apoyándose, en buena medida, en la implementación de la reforma sobre derechos humanos de 2011. Lo paradójico del caso es que en sus impulsos por "alinear, corregir y actualizar el sistema jurídico frente al nuevo parámetro constitucional fundado en los derechos humanos", ${ }^{19}$ la Corte haya dejado pasar la oportunidad de explicitar que las disposiciones jurídicas locales deben adecuarse a lo dispuesto por los derechos que descienden de las fuentes primigenias, y ser igualmente consecuentes con lo que dictan los derechos de fuente local.

Es posible que la posición asumida por la SCJN sea parte de las reacciones que se han producido al interior del Pleno en relación con el enraizamiento del control de convencionalidad y la consecuente habilitación del control difuso de constitucionalidad, que producto de la apertura de las fuentes de los derechos humanos han venido asentando una pluralidad de narrativas constitucionales, cuyo ensanchamiento, en opinión de algunos operadores, ha puesto en entredicho el carácter de órgano de cierre

18 Voto concurrente del ministro Ortiz Mena. Ibidem, pp. 90 y ss.

19 Astudillo, César, La Suprema Corte de Justicia de la Nación como tribunal constitucional. El dilema de decidir sobre qué y cómo decidir, México, Tirant lo Blanch-UNAM, Instituto de Investigaciones Jurídicas, 2019, p. 110. 
asignado a la SCJN, y su condición de poseedora de la última palabra en la interpretación nacional. ${ }^{20}$

Un contexto como el que se describe ha sido propicio para externar pronunciamientos que buscan volver a afirmar el principio de supremacía constitucional que en lo concerniente a los derechos fue profundamente modulado en la Contradicción de Tesis 293/2011, obligando a que el derecho convencional y ahora el derecho subnacional de los derechos humanos cedan ante aquél, manteniendo, en definitiva, la primacía del derecho nacional. ${ }^{21}$ Lo resuelto en las acciones de inconstitucionalidad expuestas va orientado en ese sentido.

\section{La carta de derechos de la CdMx}

La más reciente aproximación a los derechos de fuente estatal por parte de nuestro máximo tribunal se produjo en la Acción de Inconstitucionalidad 15/2017 y acumuladas 16,18 y 19/2017, en la que se impugnaron distintos contenidos de la Constitución de la $\mathrm{CdMx} .{ }^{22}$ La resolución representa el estudio más profundo que hasta ahora ha llevado a cabo sobre el significado de los catálogos de derechos humanos de las Constituciones estatales, su ámbito competencial, alcance e interpretación, y en torno a los instrumentos procesales de tutela jurisdiccional de dicha carta, en virtud de que por vez primera una entera Constitución, emanada de un proceso constituyente, de la cual nació una nueva entidad federativa en nuestro país, se sometió a revisión de compatibilidad constitucional ante nuestro tribunal constitucional.

Con el propósito de ordenar el análisis de los distintos temas impugnados, el proyecto de sentencia discutido en el Pleno de la SCJN realizó un

\footnotetext{
20 Ibidem, p. 119.

21 Existen distintos ejemplos que discurren en esta dirección. Al efecto, Cossío Díaz, José Ramón, "Evolución e involución de los derechos humanos en las sentencias de la Suprema Corte de Justicia de la Nación”, en Rubio Llorente, Francisco et al. (coords.), Estudios en homenaje a Manuel Aragón Reyes, España, Centro de Estudios Políticos y Constitucionales, 2016, p. 564.

22 Promovidas por los partidos políticos Morena y Nueva Alianza, así como la Procuraduría General de la República y la Comisión Nacional de los Derechos Humanos. Proyecto presentado por el ministro Javier Laynez Potisek, puesto a consideración del Pleno el 20 de agosto de 2018, discutido en las sesiones de 21, 23, 27, 28 y 30 de agosto, 3,4 y, finalmente, votado el 6 de septiembre, y cuyo engrose aún no se publica. El punto relativo al régimen competencial de los derechos fue aprobado por unanimidad.
} 
cuestionamiento inicial de carácter general sobre si ¿puede la CdMx ampliar derechos humanos y reconocer derechos nuevos? Para responderla, desagregó cuatro órdenes de consideraciones que llevaron a sus integrantes a pronunciarse colegiada y unánimemente sobre el régimen competencial de los derechos.

Así, la SCJN sostuvo inicialmente que una disposición jurídica distinta a la CPEUM y a los tratados internacionales, que evidentemente puede reconocerse en una Constitución estatal, pero también en una ley de desarrollo de derechos, sí puede ampliar o crear nuevos derechos humanos, ya que ello no representa una alteración indebida del bloque de constitucionalidad.

Al retomar la teoría de los derechos de Alexy, la SCJN se aproximó a los derechos como mandatos de optimización cuyo desarrollo y eficacia sólo es posible si en dicha labor se faculta a distintos órganos del Estado a expedir normas más específicas. De esta manera, se apartó de lo sostenido dos años antes, en 2015, argumentando que una actividad legislativa de esta naturaleza no es una atribución exclusiva de la Federación, a través del órgano revisor de la Constitución, ni del presidente y el Senado de la República, explicitando que un constituyente local, un órgano de reforma constitucional o incluso el legislador estatal sí tienen competencia para emitir disposiciones sobre derechos humanos, con la posibilidad de desarrollar o ampliar su contenido. Sentenció que "las entidades federativas en principio pueden válidamente establecer normas relativas a los derechos humanos en sus constituciones locales". ${ }^{23}$

En segundo lugar, afirmó que "la facultad de las entidades federativas para regular derechos humanos es congruente con los fines del federalismo", de donde deriva que "los derechos humanos son una responsabilidad compartida entre todos los poderes públicos del país", por ser una "materia de materias" que hace emanar obligaciones para todas las autoridades mexicanas dentro de los tres niveles de gobierno. Ello significa que las cartas de derechos se fundan en la pretensión de mejorar la calidad de vida de sus habitantes, lo cual se logra, entre otras cosas, mediante la ampliación del régimen de derechos de las personas que viven en su territorio, para hacer que respondan a las particularidades de cada entidad federativa, satisfagan necesidades particulares de sus colectividades y faciliten sus condiciones de ejercicio. En esta labor, las entidades deben generar las políticas públicas

23 Acción de Inconstitucionalidad 15/2017, cit., pp. 8 y ss., especialmente pp. 21 del proyecto discutido en el Pleno. 
necesarias, las disposiciones jurídicas pertinentes y las interpretaciones más favorables para su materialización. "Se debe reconocer — dice la SCJNque el federalismo abre la puerta a una sana y necesaria competencia entre entidades federativas". ${ }^{24}$

En tercer lugar, se dijo que la naturaleza constitucional de las entidades federativas, dotadas todas de autonomía, incluida la $\mathrm{CdMx}$, conduce a que no pueda existir una uniformidad de derechos en función de un "supuesto mandato de homogeneidad" que, en los hechos, invalidaría las 32 declaraciones estatales. Por el contrario, afirmó que "la innegable diversidad cultural, social y política de nuestro país" y las "grandes diferencias contextuales entre las regiones" del mismo, justifican las discordancias de derechos en cada entidad federativa, legitimando con ello la existencia del modelo federal de Estado.

De conformidad con lo anterior, subraya que:

...si bien todas las entidades federativas están obligadas como mínimo a garantizar el núcleo o contenido esencial de los derechos humanos en el ámbito de sus competencias, el sistema previsto en la Constitución Federal permite también a cada una de ellas mejorar progresivamente la calidad de vida de los ciudadanos sometidos a su jurisdicción, sin que ello necesariamente represente trato discriminatorio para quienes no se encuentren allí. El "piso mínimo" que representa la Constitución Federal sigue siendo igual en toda la República. ${ }^{25}$

Este y otros argumentos llevan a la SCJN a determinar que la Constitución de la CdMx, a pesar de tener una naturaleza que la separa del conjunto de estados de la República, cuenta con plenas atribuciones para expedir disposiciones de derechos humanos, aumentar el alcance que se les confiere, ampliar su nivel de goce y ejercicio, coadyuvando con ello al mejoramiento de su alcance y protección a nivel nacional. ${ }^{26}$ Por ende, en una opinión que deja atrás la de 2016, subraya que "esta entidad federativa puede, al igual que el resto de los estados de la República, reconocer, conceptualizar, matizar, ampliar, desarrollar o incluso crear

\footnotetext{
24 Ibidem, pp. 34 y ss., especialmente p. 37 del proyecto discutido en el Pleno.

25 Ibidem, pp. 54-56-61 del proyecto discutido en el Pleno.

26 Los elementos del régimen jurídico que separan a la Ciudad de México del resto de estados de la Federación se enuncian en la propia Acción de Inconstitucionalidad 15/2017; ibidem, y acumuladas, pp. 66 y ss. del proyecto discutido en el Pleno.
} 
derechos humanos siempre y cuando esto no contradiga el parámetro de regularidad constitucional", ${ }^{27}$

Los únicos límites establecidos a esta amplia libertad configurativa descienden de las competencias reservadas a la Federación, así como de la eventual alteración de la identidad o el contenido esencial de algún derecho reconocido en las fuentes primigenias y, en el extremo, de la potencial obstaculización de las funciones de la $\mathrm{CdMx}$, dada su especial naturaleza como capital del país y sede de los poderes federales. ${ }^{28}$

\section{LA DOCTRINA JURISPRUDENCIAL EN TORNO A LAS GARANTÍAS DE LOS DERECHOS HUMANOS DE FUENTE ESTATAL}

Como complemento a la profunda aproximación al significado de las cartas locales de derechos humanos, la SCJN retoma y reafirma los criterios sostenidos a partir del 2000, con el propósito de validar el establecimiento de un sistema de justicia constitucional, con órganos y medios de tutela para garantizar la supremacía de la Constitución de la CdMx dentro del orden jurídico de la entidad, y para proteger los derechos incorporados a su bloque de constitucionalidad.

Recordemos que desde 2000, en un embrionario acto de repliegue, la SCJN se manifestó a favor de dejar de conocer de cuestiones de constitucionalidad local, argumentando carecer de "competencia para dirimir aquellos planteamientos contra actos a los que sólo se atribuyan violaciones a la Constitución del Estado o a leyes locales, cuyo remedio corresponde establecer al Constituyente Local o a las Legislaturas de los Estados". ${ }^{29}$

Dos años más tarde, legitimó el sistema veracruzano de justicia constitucional, ${ }^{30}$ señalando que la existencia del juicio de tutela de dere-

\footnotetext{
27 Ibidem, p. 79 del proyecto discutido en el Pleno.

28 Ibidem, pp. 80 y ss. del proyecto discutido en el Pleno.

29 Tesis P./J. 30/2000, de rubro: "CONTROVERSIAS CONSTITUCIONALES ENTRE UN ESTADO Y UNO DE SUS MUNICIPIOS. A LA SUPREMA CORTE SÓLO COMPETE CONOCER DE LAS QUE SE PLANTEEN CON MOTIVO DE VIOLACIONES A DISPOSICIONES CONSTITUCIONALES DEL ORDEN FEDERAL", publicada en el Semanario Judicial..., cit., Novena Época, t. XI, abril de 2000, p. 812 .

30 Sobre este inicial sistema, que rápidamente se expandiría a muchas otras entidades federativas, acúdase a Astudillo, César, Ensayos de justicia constitucional en cuatro ordenamientos de México: Veracruz, Coahuila, Tlaxcala y Chiapas, México, UNAM, Instituto de Investigaciones Jurídicas, 2004, pp. 59 y ss.
} 
chos fundamentales se orientaba a la protección exclusiva del catálogo derechos consagrados en el parámetro local, para enseguida, mediante una argumentación similar, hacer lo propio en relación con la acción de inconstitucionalidad local. ${ }^{31}$ Con ello se produjo la creciente incorporación de mecanismos de control constitucional en la mayoría de las entidades federativas del país, y cuya heterogeneidad condujo a la necesidad de comenzar a pensar en parámetros que permitieran armonizar sus aspectos más relevantes. ${ }^{32}$

En este contexto, en 2012 nuestro máximo tribunal sostuvo que en función de que la Constitución de cada estado de la República constituye un orden jurídico superior al resto de las leyes y normas internas, era necesario reconocer que contaban con "un amplio margen de configuración constitucional y legal" para establecer tanto el diseño de su respectivo órgano de control constitucional local como los medios procesales que garantizaran la superioridad constitucional en la entidad, siempre que respetaran el marco establecido en la CPEUM. ${ }^{33} \mathrm{Y}$ dado que "los derechos humanos generan un marco de control material que también puede ser objeto de control constitucional local", se subrayó que la finalidad de dichos órganos de control y los sistemas de medios de impugnación se encuentran vinculados a la promoción, respeto, protección y garantía de los derechos humanos referidos en el artículo 1o. de la CPEUM. ${ }^{34}$

\footnotetext{
31 Controversia Constitucional 16/2000, cit., De ella derivó la Tesis P. XXXIII/2002..., cit. Véase la Tesis P.J 5/2003, de rubro: “ACCIÓN DE INCONSTITUCIONALIDAD ESTABLECIDA EN LOS ARTÍCULOS 64, FRACCIÓN III, Y 65, FRACCIÓN II, DE LA CONSTITUCIÓN POLÍtTCA DEL ESTADO DE VERACRUZ-LlaVE. No DEBE AGOTARSE PREVIAMENTE A LA ACCIÓN QUE ESTABLECE EL ARTÍCULO 105, FRACCIÓN II, DE LA CONSTITUCIÓN FEDERAL", publicada en el Semanario Judicial..., cit., t. XVII, marzo de 2003, p. 979; sobre el particular, acúdase a Astudillo, César, Derecho procesal constitucional..., cit., pp. 116 y ss., y 323 y ss., respectivamente.
}

32 Así lo hemos sostenido en Astudillo, César, Derecho procesal constitucional..., cit., pp. 293 y ss.

33 Acción de Inconstitucionalidad 8/2010, del 16 de octubre de 2012, pp. 68 y ss. La anterior ejecutoria dio lugar a la jurisprudencia P./J. 22/2012 (10a.), de rubro: "CONTROL CONSTITUCIONAL LOCAL. SU ESTABLECIMIENTO EN LAS CONSTITUCIONES DE LOS ESTADOS DEBE OBSERVAR EL MARCO PREVISTO POR LA CONSTITUCIÓN POLÍTICA DE LOS ESTAdos Unidos MeXICANOS", publicada en el Semanario Judicial..., cit., libro XIII, octubre de 2012, t. 1, p. 288.

34 Tesis P./J. 23/2012 (10a.), de rubro: "CONTROL CONSTITUCIONAL LOCAL. ES VÁLIDO ESTABLECER UN TRIBUNAL CONSTITUCIONAL Y UN SISTEMA DE MEDIOS PARA EXIGIR LA FORMA DE ORGANIZACIÓN DE LOS PODERES Y LA PROMOCIÓN Y PROTECCIÓN 
No dejó de enfatizar, enseguida, que "la competencia de los órganos jurisdiccionales locales a los que se ha encomendado tal facultad en las entidades, se constriñe al ámbito exclusivo del orden jurídico propio de cada uno de los Estados, y respecto de la violación a los derechos fundamentales contenidos en sus ordenamientos por entes del propio ámbito local o bien del municipal". ${ }^{35}$ Preocupada por mantener incontestado el orden constitucional, al inicial acto de repliegue para conocer temas que involucrasen la constitucionalidad de actos locales, sobrevino una reacción fiscalizadora, dentro de la cual patentizó que dichos medios de control no podrían contravenir al pacto federal o violentar la supremacía de la CPEUM, para lo cual toda sentencia emitida en el marco de la justicia constitucional local podría ser revisada mediante el juicio de amparo por los tribunales federales, remarcando también que los jueces locales no estarían habilitados para conocer ni ejercer el control difuso de constitucionalidad en asuntos en los que se aleguen violaciones a la CPEUM. ${ }^{36}$

Importante es destacar que dentro del Amparo Directo 6/2012, ante la identidad o coincidencia entre derechos de distinta fuente, estableció directrices iniciales para determinar el ámbito, el órgano y el medio de tutela competente; señaló que:

DE LOS DeRechos humanos en el Ámbito estatal," publicada en el Semanario Judicial..., cit., Décima Época, libro XIII, t. 1, octubre de dos mil doce, p. 288, registro digital: 2001870.

35 Amparo Directo 6/2012, del 24 de octubre de 2012, pp. 50 y 51.

36 Tesis P/J 68/2010, de rubro: “Amparo DiRECto. Procede CONTRA LAS SENTENCias de la Sala Constitucional del Tribunal Superior de Justicia del Estado DE VeracruZ, EN MATERIA de DERECHOS humanos, SALVO TRATÁNDOSE DE CUESTIONES ELECTORALES", publicada en el Semanario Judicial..., cit., Novena Época, t. XXXII, agosto de 2010, p. 5, registro digital 164177. También, Tesis 1a. XXXVIII/2016 (10a.), de rubro: "TRIBUNALES CONSTITUCIONALES LOCALES. CARECEN DE COMPETENCIA PARA CONOCER DE ASUNTOS RELACIONADOS CON VIOLACIONES A LA CONSTITUCIÓN POLÍTICA DE Los Estados Unidos MeXicAnos", publicada en el Semanario Judicial..., cit., libro 27, febrero de 2016, t. I, p. 686. Asimismo, las tesis aisladas 1a. XXXVIII/2016, de rubro: "TRIBUNALES CONSTITUCIONALES LOCALES. CARECEN DE COMPETENCIA PARA CONOCER DE ASUNTOS RELACIONADOS CON VIOLACIONES A LA CONSTITUCIÓN POLÍTICA DE LOS ESTAdos Unidos MeXICANos", publicada en el Semanario Judicial..., cit., libro 27, febrero de 2016, t. I, p. 686, registro digital 2010978. También, 1a. XXXIX/2016, de rubro: “CoNTROL DIFUSO DE CONSTITUCIONALIDAD. NO TIENE EL ALCANCE DE QUE LOS TRIBUNALES CONSTITUCIONALES LOCALES CONOZCAN DE ASUNTOS RELACIONADOS CON VIOLACIONES A LA Constitución Política de los Estados Unidos MeXicANos, RESPECTO DE ASUNTOS QUE NO SEAN DE SU COMPETENCIA", publicada en la Gaceta del Semanario Judicial..., cit., Décima Época, libro 27, febrero de 2016, t. I, p. 668, registro digital: 2010960. 
...el particular, ante la estimación de la violación a un derecho humano que se encuentra reconocido en la Constitución Política de los Estados Unidos Mexicanos y a la vez —en similares términos o idénticos-, en la Constitución Estatal, se encuentra en aptitud de acudir a reclamar su vulneración en alguno de los dos fueros conforme a la norma que corresponda; esto es, puede acudir a la jurisdicción constitucional local, en la vía de protección de los derechos humanos a invocar la violación a su derecho fundamental reconocido en la constitución de la entidad o en alguna ley de la misma; o bien, interponer el juicio de amparo indirecto, por la violación a un derecho humano reconocido en la Constitución General de la República, caso éste último en el que no requiere agotar la instancia estatal, puesto que no reclama la norma local, sino la disposición de la Norma Suprema. ${ }^{37}$

Ahora bien, en lo concerniente a la impugnación de la Constitución de la CdMx, nuestro máximo tribunal decretó la constitucionalidad del sistema de justicia constitucional, con todo y su despliegue de mecanismos de control, entre los que se encuentran las acciones y controversias constitucionales, las acciones por omisión legislativa, la revisión de la validez de los referéndums, así como las acciones de cumplimiento frente a los poderes públicos, entre otros, las cuales serán ejercitadas ante la Sala Constitucional del Tribunal Superior de Justicia, como una instancia de carácter permanente a la que se le reconoce como "la máxima autoridad local en materia de interpretación de la Constitución Política de la Ciudad de México" (artículo 36)..$^{38}$

Al pronunciarse sobre su legitimidad, aprovechó para realizar un más acabado ejercicio de acotación de sus alcances, señalando que "dentro de los medios locales de control de constitucionalidad, la actividad de control constitucional que realicen los jueces locales debe circunscribirse sólo al contraste de normas o actos locales que se impugnen por estimarse directamente violatorios de los derechos reconocidos por la Constitución local". ${ }^{39}$

\footnotetext{
37 Amparo Directo 6/2012, cit., p. 73.
}

38 Sobre el significado, alcance y finalidad de estos mecanismos de control y de las correspondientes salas constitucionales, remitimos, en perspectiva comparada, a lo que hemos sostenido en Astudillo, César, Derecho procesal constitucional..., cit., pp. 217 y ss., especialmente, pp. 269 y ss.

39 Acción de Inconstitucionalidad 15/2017, cit., p. 364 del proyecto discutido en el Pleno. 
Asimismo, avanzó un conjunto de prohibiciones que los órganos de control de constitucionalidad local deben respetar, entre los que se encuentra la imposibilidad de alterar la identidad o el contenido esencial de algún derecho reconocido en el bloque de constitucionalidad y la oposición a la doctrina jurisprudencial sustentada por la SCJN en materia de derechos humanos. Enfatizó, además, las obligaciones que al día de hoy recaen en la entera judicatura local, conminándolos a interpretar sistemáticamente los derechos locales y los reconocidos en las fuentes primigenias, y a mantener un estricto respeto por los criterios y principios de interpretación previstos en el artículo 1o. de la CPEUM. ${ }^{40}$

Como corolario de lo anterior, es importante destacar que el régimen democrático que auspicia una Constitución profundamente asentada en un vasto caudal de derechos y libertades, se ha hecho acompañar de un robusto sistema de justicia constitucional que contempla instrumentos procesales adecuados, accesibles y efectivos para impugnar la constitucionalidad y convencionalidad de actos y normas locales, al margen y con motivo de su aplicación, ante una sala constitucional dispuesta ex profeso para ser la garante del naciente orden constitucional de la CdMx, dotándola así de todos los elementos que permiten augurar la materialización del proyecto político, social y cultural que le subyace. ${ }^{41}$

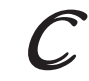

40 Ibidem, pp. 366 y 367 del proyecto discutido en el Pleno.

41 Sobre las características del derecho a un recurso efectivo, acúdase a Astudillo, César, Estudios electorales, México, Tirant lo Blanch, 2019, pp. 165 y ss. 